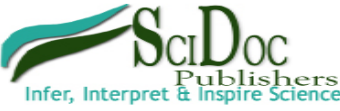

\author{
International Journal of Clinical Pharmacology \& Toxicology (IJCPT) \\ ISSN 2167-910X
}

\title{
Need for Pharmacogenomic Information Also for Generic Medications; Recommendation of the European Society of Pharmacogenomics and Theranostics (ESPT)
}

Editorial

Prof Gerard Siest

ESPT President, Lorraine University, Cardiovascular Genetics Research Unit, 30 rue Lionnois54000 NANCY, France.

\section{*Corresponding Author:}

Prof Gerard Siest,

ESPT President, Lorraine University, Cardiovascular Genetics Research Unit, 30 rue Lionnois54000 NANCY, France.

Tel: +33383682170

E-mail: erard.siest@univ-lorraine.fr

Received: June 01, 2012

Published: October 01, 2012

Citation: Prof Gerard Siest (2012) Need for Pharmacogenomic Information Also for Generic Medications; Recommendation of the European Society of Pharmacogenomics and Theranostics (ESPT), Int J Clin Pharmacol Toxicol. 1(2e), 1. doi: http://dx.doi.org/10.19070/2167910X-120002e

Copyright: (C) 2012 Prof Gerard Siest. This is an open-access article distributed under the terms of the Creative Commons Attribution License, which permits unrestricted use, distribution and reproduction in any medium, provided the original author and source are credited.

\section{Clopidogrel as a prototype}

As of 2007, PLAVIX (the original brand name of Clopidogrel) had been the second top selling drug in the world and is, presently, prescribed and marketed in nearly 110 countries. Clopidogrel is currently the thienopyridine of choice for dual antiplatelet therapy (in combination with aspirin) in patients with the full spectrum of acute coronary syndrome and in patients undergoing percutaneous coronary intervention and stenting. In a plethora of pharmacogenomic studies on PLAVIX, it has been shown that Clopidogrel is a prodrug that requires biotransformation to an active metabolite by CYP450 enzymes (mainly CYP2C19) and paraoxonase 1 (PON-1). There is significant inter-individual variability in the response to PLAVIX, with up to $40 \%$ of patients being classified as non-responders, poor responders or resistant to this drug. Pharmacogenomic information on PLAVIX reveals that genetic polymorphisms of CYP enzymes (most commonly CYP2C19*2), PON-1 and also the ABCB 1 transporter contribute to variation in the response of individual patients to PLAVIX. In March 2010, the FDA released a "Boxed Warning" on PLAVIX addressing the need for pharmacogenomic testing (for detecting CYP2C19 lossof-function polymorphisms) to identify patients' altered PLAVIX metabolism, and thus their risk for a suboptimal clinical response to this drug. Based on an expanding database, and as an approach to the FDA boxed warning, the ACCF/AHA-convened writing committee developed an evidence-based guideline: "Recommendations for Practice", in July 2010. These documents were validated in France in October 2010 and the SmPC (Summary of Product Characteristics) of PLAVIX was updated accordingly by the French regulatory agency (AFSSAPS).

\section{Situation in France}

Generic Clopidogrel has been available on the market for a few years and is currently produced by several pharmaceutical companies all over the world. In France, for instance, generic versions of Clopidogrel have been available since 2009, with some 21 French generic products currently on the market. The majority of generic versions, however, differ from the branded product, PLAVIX, by the salt formulation. Only the generic Clopidogrel marked by Zentiva, (the European generics business for the Sanofi group), has the same formulation as PLAVIX. Although this structural difference may potientially have an impact on the pharmacokinetics of Clopidogrel, it does not have an effect on the pharmacogenetic conversion to active metabolites. Therefore, the same pharmacogenetic information as in the Plavix label should be present in the generic drug. While pharmacogenetic characteristics of PLAVIX have been well documented and are easily accessible, the relevant data for generic Clopidogrel is less available. In France, specifically, a recent survey carried out on the pharmacogenomic information included in the drug labels of marketed French generic Clopidogrel products found that of 21, only 5 generics provided the prescribers and patients with the applicable pharmacogenomic information.

\section{Call}

The ESPT calls for a harmonized and consensus-based approach to an updatable drug labeling of generic versions for pharmacogenomic information, as is the case for the original drug. This requirement is, undoubtedly, not limited to Clopidogrel and should be extrapolated to all medications which are marketed as both branded and generic versions.

\section{Prepared by}

Laetitia Albertini. PharmD

Gérard Siest. PharmD, PhD

Payman Shahabi. MD

Sophie Visvikis-Siest. PhD

Cardiovascular Genetic Research Unit

University of Lorraine

30 rue Lionnois

54000 NANCY- FRANCE

\section{Endorsed by ESPT Board Members}

Pr. Adrian Llerena - Badajoz, ES

Dr. Adriano M Henney - Macclesfield, UK

Pr. Vangelis G Manolopoulos - Alexandroupolis, GR

Pr. Ron H Van Schaik - Rotterdam, NL

Dr. George P Patrinos - Patras, GR

Pr. Janja Marc - Ljubljana, SL

Dr. Sophie Visvikis-Siest - Nancy, FR

Pr. Gerard Siest - Nancy, FR 